\title{
Detection of Oropouche virus segment $S$ in patients and in Culex quinquefasciatus in the state of Mato Grosso, Brazil
}

\author{
Belgath Fernandes Cardoso', Otacília Pereira Serra', Letícia Borges da Silva Heinen',

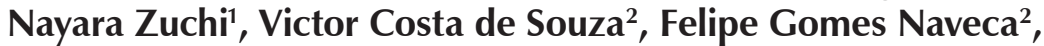 \\ Marcelo Adriano Mendes dos Santos ${ }^{3}$, Renata Dezengrini Slhessarenko ${ }^{1 /+}$ \\ ${ }^{1}$ Universidade Federal de Mato Grosso, Faculdade de Medicina, Programa de Pós-Graduação em Ciências da Saúde, Cuiabá, MT, Brasil \\ ${ }^{2}$ Fundação Oswaldo Cruz, Instituto Leônidas e Maria Deane, Manaus, AM, Brasil \\ ${ }^{3}$ Laboratório Central, Secretaria de Estado de Saúde, Cuiabá, MT, Brasil
}

This study aimed to investigate the circulation of Orthobunyavirus species in the state of Mato Grosso (MT) Brazil. During a dengue outbreak in 2011/2012, 529 serum samples were collected from patients with acute febrile illness with symptoms for up to five days and 387 pools of female Culex quinquefasciatus captured in 2013 were subjected to nested-reverse transcription-polymerase chain reaction for segment $S$ of the Simbu serogroup followed by nucleotide sequencing and virus isolation in Vero cells. Patients (5/529; 0.9\%) from Cuiabá $(n=3)$, Várzea Grande $(n=1)$ and Nova Mutum $(n=1)$ municipalities were positive for the $S$ segment of Oropouche virus $($ OROV). Additionally, eight $/ 387 \mathrm{Cx}$. quinquefasciatus pools were positive for the segment, with a minimum infection rate of 2.3. Phylogenetic analysis indicated that all the samples belong to the subgenotype Ia, presenting high homology with OROV strains obtained from humans and animals in the Brazilian Amazon. The present paper reports the first detection of an Orthobunyavirus, possibly OROV, in patients and in Cx. quinquefasciatus mosquitoes in MT. This finding reinforces the notion that arboviruses frequently reported in the Amazon Region circulate sporadically in MT during dengue outbreaks.

Key words: OROV - Orthobunyavirus - Mato Grosso - mosquitoes - phylogenetic analysis

Arboviruses (arthropod-borne viruses) are widely dispersed in sylvatic tropical areas around the globe. However, some of these viruses have the ability to maintain urban transmission cycles involving humans as susceptible hosts and highly anthropophilic vector species, such as dengue virus (DENV), yellow fever virus (YFV), Chikungunya virus and Oropouche virus (OROV), producing large epidemics (Moreli \& Costa 2013).

The Bunyaviridae family currently contains more than 350 species classified into five genera according to morphological, antigenic and molecular properties (Elliott 2014). The Bunyaviridae virion is spherical and enveloped, approximately $100 \mathrm{~nm}$ in diameter, containing three negative single-stranded genomic RNA segments ( $\mathrm{S}, \mathrm{M}$ and $\mathrm{L}$ ) surrounded by helicoidal nucleocapsids. The S-RNA is the most conserved RNA segment of orthobunyaviruses. Due to this property, S-RNA is largely used for phylogenetic reconstruction, including for OROV isolates (Saeed et al. 2000, Nunes et al. 2005, Acrani et al. 2010, Vasconcelos et al. 2011, Hang et al. 2014).

doi: 10.1590/0074-02760150123

Financial support: CNPq, CAPES, UFMT

BFC, OPS, LBSH and NZ were recipients of CAPES Master scholarships. + Corresponding author: renatadezengrini@yahoo.com.br

Received 25 March 2015

Accepted 6 August 2015
The Orthobunyavirus genus comprises 170 viruses, which are assembled into 48 species in 19 recognised serogroups (Chowdhary et al. 2012, Gauci et al. 2015). The Simbu serogroup is the most important epidemiologically and includes 25 antigenically related viruses classified into seven complexes. These seven include Simbu, Manzanilla, Oropouche, Akabane, Sathuperi, Shamonda and Shuni, which have been reported in all continents (Yanase et al. 2012). The Oropouche complex includes the OROV, Jatobal, Iquitos, Leanyer, Oya and Thimiri viruses. Of these, only OROV circulation is recognised in humans in Brazil. OROV is the most frequent Orthobunyavirus in the Amazon Region. South American strains of the virus obtained from human cases registered in Peru, Panamá, Brazil and Trinidad are classified mainly as genotypes I, II and III (Saeed et al. 2000, Vasconcelos et al. 2011).

OROV is transmitted in a sylvatic cycle that potentially involves birds, sloths and primates as amplifying hosts and Aedes (Oclerotatus) serratus, Coquillettidia venezuelensis and Culicoides spp as vectors (Figueiredo 1999). In villages located in degraded forests and in urbanised areas near forests humans are believed to act as amplifying hosts and Culicoides paraensis biting midges are believed to be the most important vector. Culex quinquefasciatus has been considered a secondary urban anthropophilic vector (Vasconcelos et al. 1989, Pinheiro et al. 1997). Clinical manifestations develop after threeeight days of incubation; Oropouche fever lasts for twoseven days, might be accompanied by exanthema and, in rare cases by aseptic meningitis, which is more frequent 
in immunocompromised individuals and children. Clinical recurrence is observed in 56\% of the cases (Pinheiro et al. 1981b, Bastos et al. 2012).

OROV was first isolated from a febrile patient in Vega de Oropouche, Trinidad \& Tobago in 1955 and from a Coquilletidia venezuelensis mosquito pool in 1960 (Anderson et al. 1961). In Brazil, OROV was first isolated from a sloth (Bradypus tridactylus) and from Ochlerotatus serratus mosquitoes in 1960 during the construction of the Belém-Brasília Highway in the northern region of the country (Pinheiro et al. 1962). The first epidemic involved 11 thousand individuals and was registered in 1961 in a city of the state of Pará (PA), northern Brazil. Serological studies indicate that at least 357,000 individuals were infected by OROV in the Brazilian Amazon between 1961-1996, especially in PA (Pinheiro et al. 1986). Epidemics were also registered in other states, including Amazonas (AM) (Borborema et al. 1982) and Amapá (AP) in 1980 (Pinheiro 1983), Maranhão (MA) and Tocantins in 1988 (Vasconcelos et al. 1989) and Rondônia (RO) in 1991 (Terzian et al. 2009). The last large epidemic was reported in 1996, involving PA, AM and Acre (AC) (Pinheiro et al. 1998).

In the Southeast and Central-West Regions of Brazil, OROV has also been reported. In Ribeirão Preto, state of São Paulo, OROV antibodies were detected in two urban residents (Figueiredo et al. 1986). In the state of Minas Gerais (MG), OROV was recovered from a primate (Nunes et al. 2005). Additionally, $0.7 \%$ of 1,201 inhabitants of cities from southern state of Goiás presented antibodies against OROV in 1973. The prevalence of antibodies in cities of the Amazon Region is generally up to 3\% (Pinheiro et al. 1981b). Residents in two cities from PA affected by the Cuiabá-Santarém Highway, on the border with MT, presented anti-OROV IgM antibodies (Nunes et al. 2009). Recently, a nonhuman primate tested positive for OROV in a haemagglutination inhibition test in the Pantanal, state of Mato Grosso do Sul (MS) (Batista et al. 2012) and another exhibited a serological response to the virus in Cerrado of MS (Batista et al. 2013).

MT, located in Central-West Brazil, presents a tropical climate and particular ecological conditions, such as biodiversity and is distributed in sylvatic areas of the Amazon, Cerrado and Pantanal biomes, conditions that favour arbovirus circulation. Local urban areas are also susceptible to arbovirus circulation. The occurrence of the Mayaro and Saint Louis encephalitis (SLEV) viruses was recently reported during a dengue outbreak in Cuiabá, the capital and the largest city of MT (Zuchi et al. 2014, Heinen et al. 2015). Therefore, the aim of this study was to investigate the circulation of the Orthobunyavirus from the Simbu serogroup in patients with febrile illness and in $C x$. quinquefasciatus mosquitoes captured in MT.

\section{SUBJECTS, MATERIALS AND METHODS}

Clinical samples and ethics statement - In this study, serum samples from 529 patients with acute febrile illness persisting for up to five days from 17 cities of MT were obtained between October 2011-July 2012 in the Public Health Central Laboratory (LACEN-MT). All samples had been tested previously for DENV serotypes and YFV by virus isolation followed by immunofluorescence and molecular techniques.

Serum samples were stored at $-80^{\circ} \mathrm{C}$ at the Laboratory of Virology of the School or Medicine of the Federal University of Mato Grosso (UFMT). The viral RNA was extracted (Qiamp viral RNA mini kit; Qiagen, Germany) and immediately converted into genus-specific cDNA. Nested-reverse transcription-polymerase chain reaction (RT-PCR) for the segment S of the Simbu serogroup of the Orthobunyavirus genus was performed (Moreli et al. 2002).

The procedures involving human samples were previously approved by the institutional review board of the Julio Muller University Hospital Ethical Committee on Research under the register 100/2011. All epidemiological data obtained through the Information System for Notifiable Diseases records and/or directly from the patients were handled anonymously and confidentially.

Sampling of Culex mosquitoes in Cuiabá - Because most of the patients included in the study are residents of the metropolitan area of Cuiabá, a parallel study was conducted with mosquitoes. Specimens of $C x$. quinquefasciatus $(\mathrm{n}=387)$ were captured between 01:00 pm-05:00 pm during the rainy season (January-April 2013) with Nasci aspirators and hand nets from three places in each of 200 censitary sectors that were randomly selected in Cuiabá. The mosquitoes remained in the laboratory for at least $12 \mathrm{~h}$, receiving artificial feeding with sugar water until identification with a dichotomy key (Forattini 2002) and with a molecular approach using semi-nested-PCR for $C x$. quinquefasciatus (Smith \& Fonseca 2004). Pools containing one-35 mosquito specimens according to place of capture, genus, species and sex were stored at $-80^{\circ} \mathrm{C}$. Only female pools were included in the present study.

Pools were macerated and diluted in RNAse-free phosphate-buffered solution; $400 \mu \mathrm{L}$ of the supernatant was used for total RNA and total DNA extraction (Trizol; Invitrogen, USA) and cDNA was immediately synthesised with Superscript III (Invitrogen) following the manufacturer's instructions. The extracted DNA was used for molecular confirmation of the mosquito species.

Semi-nested-PCR for Culex species - The protocol used for $C x$. quinquefasciatus identification was performed in 78 pools that were identified as Culex pipiens complex and 102 of Culex spp according to Smith and Fonseca (2004) with few modifications. In the first reaction, the primers B1246s $(0.2 \mu \mathrm{M})$ and F1475 $(0.2 \mu \mathrm{M})$ were used with the following cycling conditions: $94^{\circ} \mathrm{C}$ for $5 \mathrm{~min}, 35$ cycles of $94^{\circ} \mathrm{C}$ for $30 \mathrm{~s}, 55^{\circ} \mathrm{C}$ for $30 \mathrm{~s}$ and $72^{\circ} \mathrm{C}$ for $1 \mathrm{~min}$ and a final extension at $72^{\circ} \mathrm{C}$ for $5 \mathrm{~min}$. This PCR product was subjected to semi-nested-PCR using $1 \mathrm{ng}$ of PCR product, the primers B1246s $(0.2 \mu \mathrm{M})$ and ACEquin $(0.8 \mu \mathrm{M})$ and cycling conditions as follows: $94^{\circ} \mathrm{C}$ for $5 \mathrm{~min}, 35$ cycles of $94^{\circ} \mathrm{C}$ for $30 \mathrm{~s}, 57^{\circ} \mathrm{C}$ for 30 $\mathrm{s}, 72^{\circ} \mathrm{C}$ for $1 \mathrm{~min}$ and final extension of $72^{\circ} \mathrm{C}$ for $5 \mathrm{~min}$.

Nested-PCR for segment $S$ of orthobunyaviruses belonging to the Simbu serogroup - The protocol described by Moreli et al. (2002) was used to amplify segment $\mathrm{S}$ 
from the genome of orthobunyaviruses (961 bp) with a few modifications. Briefly, cDNA $(8 \mu \mathrm{L})$ was amplified with BUN-S primer and was then subjected to a PCR reaction containing 10x PCR buffer, $\mathrm{MgCl}_{2}(2 \mathrm{mM})$, dNTPs $(0.2 \mathrm{mM})$, the primers BUN-S $(+)(0.6 \mu \mathrm{M})$ and BUN-C (-) $(0.6 \mu \mathrm{M}), 1 \mathrm{U}$ of DNA polymerase (LGC Biotecnologia, Brazil) and ultrapure water for $50 \mu \mathrm{L}$ of reaction following the cycling conditions described by the authors. The second PCR reaction targets a $300-$ bp region of Simbu serogroup members (BS-S and BS-C primers). This reaction was performed using $2 \mu \mathrm{L}$ of the product of the first reaction and the same concentrations of reagents and cycling conditions, with a final volume of $25 \mu \mathrm{L}$. cDNA from an OROV strain (BeAn19991) and no template were included as controls; precautions to avoid contamination were undertaken during procedures. The positive control was sequenced to rule out contamination.

Nucleotide sequencing and phylogenetic analysis The sequencing was performed using POP- $7^{\mathrm{TM}}$ and an ABI 3130 DNA Sequencer. Approximately 10-40 ng of purified nested-PCR product (300 bp of segment S) was amplified following the BigDye Terminator v.3.1 Cycle Sequencing protocol. The sequences were initially filtered by applying a Phred score cut-off of $\leq 20$ using the Sequencing Analysis (Applied Biosystems, v.5.3.1) software, a procedure that was kindly performed by the Leônidas e Maria Deane Institute, Oswaldo Cruz Foundation (Fiocruz) Amazônia. Only the filtered sequences were considered for contig assembly after trimming the low-quality ends. Geneious R6 (Biomatters, v.6.0.5) was used for this purpose. The contigs were compared with reference sequences through the nucleotide Basic Local Alignment Search Tool (BLASTn, GenBank, PubMed).

Phylogenetic analysis included several nucleotide sequences of segment $\mathrm{S}$ from OROV strains available from GenBank (PubMed, National Center for Biotechnology Information). After alignment with CLUSTALW and analysis using Molecular Evolutionary Genetics Analysis (MEGA v.5.05), the best model of nucleotide substitution was determined by jModelTest (v.2.2.6). A phylogenetic tree was generated using a region of the $\mathrm{N}$ protein of OROV with 1,000 bootstrap replicates. The evolutionary history was inferred using the neighbour-joining method with Tamura three-parameter distance model and the rate variation among sites was modelled with a gamma distribution (shape parameter $=1$ ). Outgroups included the Buttonwillow, Faceys Paddock, Ingwavuma, Mermet, Aino, Tinaroo and Akabane orthobunyaviruses.

Inoculation in cell culture - Samples positive for OROV according to nested-RT-PCR and nucleotide sequencing were diluted 1:10 and inoculated into 24-well polystyrene plates containing Vero cells (ATCC CCL81). The cells were cultivated in RPMI-1640 medium supplemented with $5 \%$ foetal bovine serum (FBS). After the incubation period $(2 \mathrm{~h})$ at $37^{\circ} \mathrm{C}$ and $5 \% \mathrm{CO}_{2}$, the inoculum was removed and the monolayer was washed with RPMI-1640 medium containing antimycotic agents and antibiotics. The culture medium was replaced and the cells were observed daily for seven-10 days. After this period, the monolayers were harvested for total RNA extrac- tion (Trizol) followed by nested-RT-PCR and sequencing, as previously described. Three passages were performed with the supernatant to ensure viral amplification.

Data analysis - The minimum infection rate (MIR) was calculated with the formula (number of positive pools/total specimens tested) x 1,000 , considering the total of $C x$. quinquefasciatus specimens tested $(3,425$ mosquitoes). The geospatial data were analysed with ArcMap (ESri ArcGIS, v.9.3).

Accessions - Nucleotide sequences from the segment $\mathrm{S}$ of OROV obtained in the present study were deposited in GenBank and PubMed with the accessions KP310500-KP310507 (mosquito pools) and KP347671KP347674; KP954633 (human samples).

\section{RESULTS}

Characterisation of the study population - Among the 529 human samples included in the study, $461(87.2 \%)$ were obtained from the metropolitan area of Cuiabá. In this subset, 396 (74.9\%) were from Cuiabá, 65 (12.3\%) were from Várzea Grande and 68 (12.8\%) were from the other 15 cities of MT (Fig. 1). From this total, 255 (48.2\%) were men, 263 (49.7\%) were nonpregnant women and six $(2.3 \%)$ were pregnant when the sample was collected. The age distribution consisted of 239 (45.3\%) patients aged 20-39 years, 94 (17.8\%) patients aged 40-59 years and $63(12 \%)$ patients aged 15-19 years. Regarding the ancestral lineages, which were inferred by skin colour, $314(59.4 \%)$ of the patients considered themselves pardo (a multiethnic group that represents over $42 \%$ of the total Brazilian population) (Lins et al. 2010). Additionally, 511 $(96.6 \%)$ of the patients were residents in urban areas, 24 $(4.6 \%)$ of the patients reported a recent history of travel or visit to rural or sylvatic areas and 267 (50.5\%) of the patients denied any previous history of a similar disease.

Detection of the segment $S$ of OROV in serum samples of febrile patients from MT - In this study, 5/529 $(0.9 \%)$ serum samples of patients suspected of harbouring dengue who were treated at primary health care units were found to be positive for segment S of OROV according to nested-RT-PCR and subsequent nucleotide sequencing and virus isolation (Table I).

Four of the positive patients were residents of the metropolitan area of Cuiabá. All cities with positive patients are accessible by the Cuiabá-Santarém Highway (Fig. 1). Four of the patients were women and positive patients were identified only after two-three days of experiencing symptoms.

Cx. quinquefasciatus captured in Cuiabá were positive for the segment $S$ of OROV - Among the 387 pools of Cx. quinquefasciatus, eight (2\%) were positive for segment S of OROV by nested-RT-PCR and confirmed by nucleotide sequencing, with a MIR of 2.3 per 1,000 $C x$. quinquefasciatus specimens. Although positive pools were identified in every month of sampling, $50 \%$ of the positive pools were captured in April 2013. Additionally, positive pools were identified in all of the administrative regions of the city (Fig. 2), three/eight of which were in the north (Table II). 


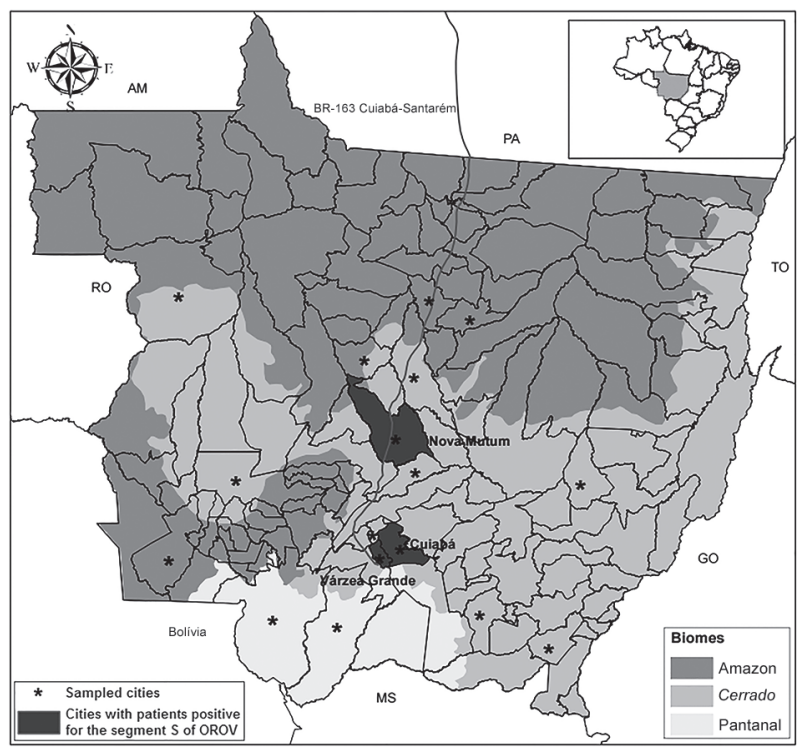

Fig. 1: distribution of the samples included in the study and the five patients with acute febrile illness positive for the segment S of Oropouche virus (OROV) by nested-reverse transcription-polymerase chain reaction per city of residency in the state of Mato Grosso, Brazil. Brazilian states: AM: Amazonas; GO: Goiás; MS: Mato Grosso do Sul; PA: Pará; RO: Rondônia; TO: Tocantins.

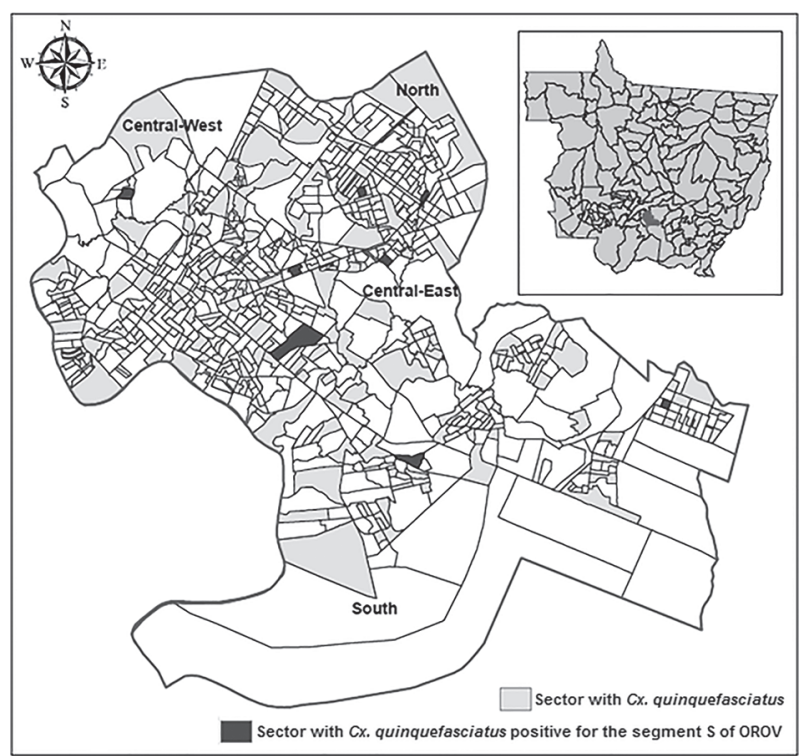

Fig. 2: distribution of Culex quinquefasciatus pools captured and positive for the segment $\mathrm{S}$ of Oropouche virus (OROV) according to the censitary map in Cuiabá, state of Mato Grosso, Brazil.

Phylogenetic analysis of a partial region of the OROV nucleocapsid protein - The phylogenetic analysis of the human (KP347671-KP347674; KP954633) and Cx. quinquefasciatus (KP310500-KP310507) samples positive for segment $\mathrm{S}$ of OROV indicate a close proximity between sequences of the virus belonging to subgenotype Ia (Fig. $3)$. The nucleotide similarity of the samples obtained in this study ranged from $98-100 \%$ for the sequences of

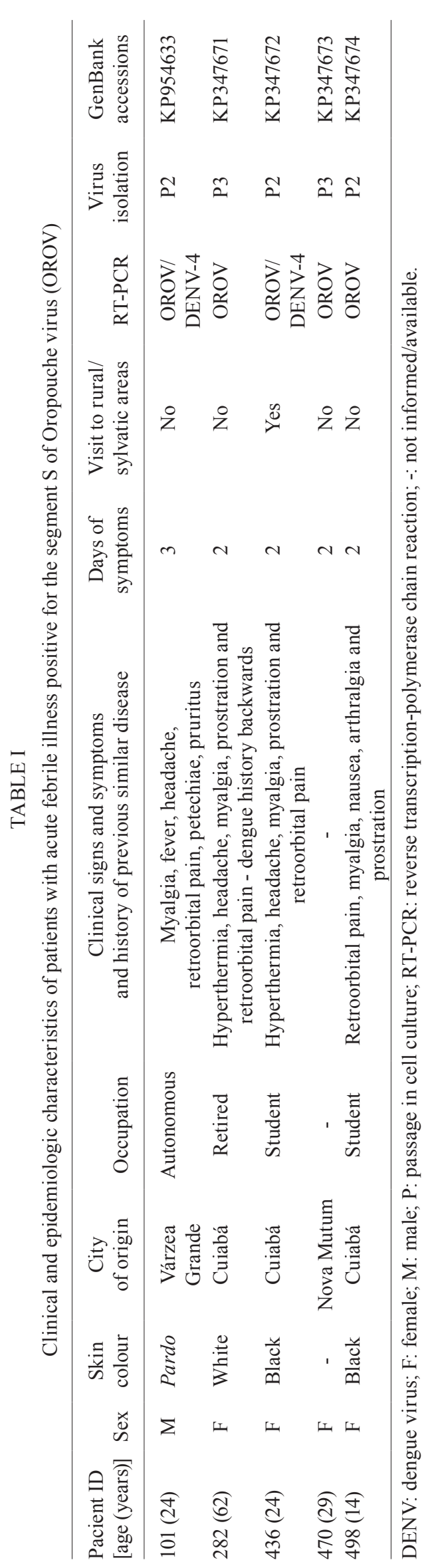


TABLE II

Culex quinquefasciatus female pools captured in Cuiabá, state of Mato Grosso, Brazil between January-April 2013 positive for the segment S of Oropouche virus (OROV) and dengue virus 4 (DENV-4)

\begin{tabular}{|c|c|c|c|c|c|c|c|}
\hline Pool ID & Engorged & $\begin{array}{l}\text { Specimens } \\
\text { (n) }\end{array}$ & Region & Capture date & RT-PCR & Virus isolation & $\begin{array}{c}\text { GenBank } \\
\text { accessions }\end{array}$ \\
\hline 116 & Yes & 34 & Central-West & 23 January & OROV & - & KP310505 \\
\hline 549 & Yes & 1 & Central-East & 20 February & OROV/DENV-4 & - & KP310504 \\
\hline 632 & No & 2 & Central-East & 28 February & OROV & p3 & KP310506 \\
\hline 833 & Yes & 19 & South & $6 \mathrm{March}$ & OROV/DENV-4 & p2 & KP310507 \\
\hline 1229 & No & 2 & South & 9 April & OROV & - & KP310500 \\
\hline 1256 & No & 2 & North & 10 April & OROV & - & KP310501 \\
\hline 1458 & No & 1 & North & 22 April & OROV & p2 & KP310502 \\
\hline 1521 & Yes & 3 & North & 24 April & OROV & - & KP310503 \\
\hline
\end{tabular}

p: passage in cell culture; RT-PCR: reverse transcription-polymerase chain reaction; -: negative through virus isolation.

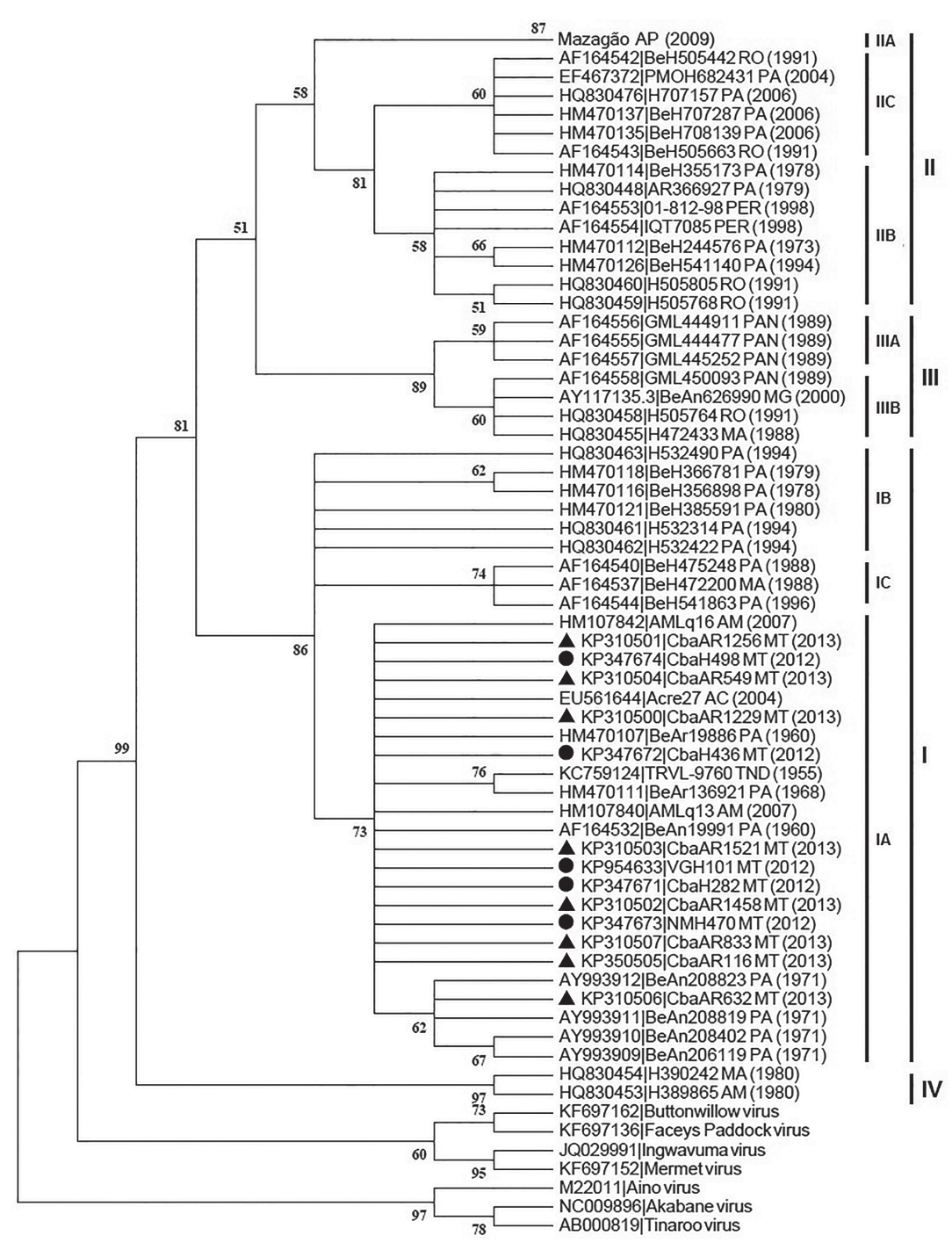

Fig. 3: phylogenetic tree of Oropouche virus nucleoprotein partial sequences obtained from humans (KP954633, KP347671-KP347674) and from Culex quinquefasciatus (KP310500-KP310507) in the state of Mato Grosso and reference strains from genotypes Ia-c, IIa-c, IIIa-b and IV of the virus outgroup: Buttonwillow (KF697162), Faceys Paddock (KF697136), Ingwavuma (JQ029991), Mermet (KF697152), Aino (M22011), Tinaroo (AB000819) and Akabane (NC009896) viruses. The tree was obtained through neighbour-joining method with bootstrap of 1,000 replicates. The distance was calculated by the transition/transversion rate, Tamura three-parameter method and gamma distribution (distribution parameter gamma $=1)$. $\bullet$ : human samples; $\mathbf{\Delta}$ : arthropod pools. 

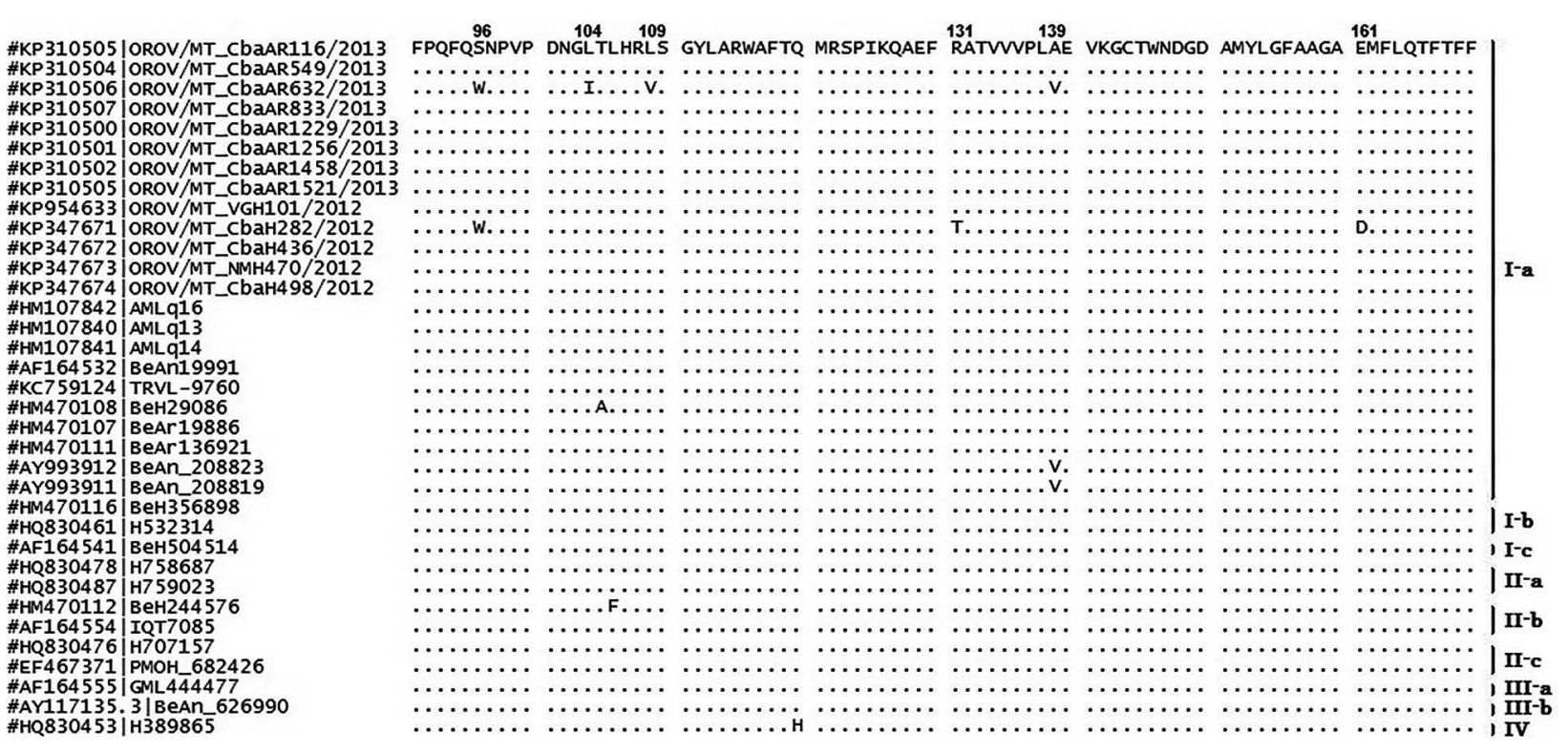

Fig. 4: alignment of the deduced amino acid (aa) nucleoprotein partial sequence of Oropouche virus (OROV) obtained from Culex quinquefasciatus pools (OROV/MT_CbaAR) and humans (OROV/MT CbaH and OROV/MT NMH) with acute febrile illness from the state of Mato Grosso, Brazil compared to reference strains available at GenBank database. Sites with aa substitutions are highlighted according to their position.

OROV strains obtained from humans in Manaus, AM (AMLq16 and AMLq13), AC (BR/2004/Acre27) and from sloths (B. tridactylus) captured in PA (BeAn208823, BeAn208819, BeAn206119, BeAn208402).

Differences of zero-eight nucleotides were observed between segment $\mathrm{S}$ OROV sequences obtained from samples in the study. The highest divergence was verified between the sequences obtained from human samples 436, 498 and mosquito pool 632 (1.23 of distance). Human samples 282 of Cuiabá and 470 of Nova Mutum and all other sequences obtained from $C x$. quinquefasciatus presented $100 \%$ identity.

The sequence obtained from mosquito pool 632 presented the highest divergence of the nucleotide sequences obtained in the present study. At position 339, a silent cytosine-to-thymine mutation was observed, similar to that observed in OROV isolate sequences obtained in AP in 2009 belonging to genotype IIa. At position 418, a cytosine-to-thymine mutation resulted in an alanine-to-valine amino acid (aa) substitution at residue 139 (Fig. 4). This point mutation has been described only in animal strains belonging to subgenotype Ia obtained from sloths ( $\mathrm{Bra}$ dypus trydactilus) in PA (BeAn206119, BeAn208402, BeAn208819, BeAn208823). In sequences obtained from human samples 282 and 436, a guanine was substituted for an adenine at position 240; this substitution is commonly found in isolates belonging to subgenotype IIIb (BeAn626990, GML450093, H472433, H505764).

DENV-4 was identified in two patients (KP694222KP694223) in previous studies and in two pools of mosquitoes (KP694224-KP694225) that were positive for both viruses (data not shown).

\section{DISCUSSION}

Dengue outbreaks are reported every year in MT. Arboviruses represent a major issue for public health in tropical areas worldwide. There is evidence of OROV circulation in all neighbouring states, but no reports exist of OROV studies in MT.

Factors such as deforestation and new agricultural boundaries have contributed to the emergence of Oropouche fever in Brazil (Murphy 1998). It is estimated that more than 30 outbreaks have occurred in the country, constituting the second most frequent arbovirus in terms of number of cases reported to the Ministry of Health (Vasconcelos et al. 1989, Moreli et al. 2002). It is likely that the circulation of OROV and other orthobunyaviruses is underestimated in Brazil because the disease is clinically mistaken for dengue fever due to poor laboratorial differential diagnosis.

In this study, segment S of OROV was detected in five febrile patients from three cities located in the metropolitan area of Cuiabá and in northern MT during a dengue outbreak in 2012. The Cuiabá-Santarém Highway is accessed by all three cities. The central Amazon Region extends from northeast PA to the Porto VelhoManaus-Venezuela Highway and is constantly evolving due to the soybean outflow (Becker 2001). A similar situation exists in the region surrounding the CuiabáSantarém Highway, which involves areas of Cerrado and Amazon and presents an intense flux of animals and persons, thereby propitiating arbovirus dispersion. The indiscriminate anthropic interference with sylvatic areas via deforestation and uncontrolled urbanisation also contributes to the large environmental impact and may result in the emergence or re-emergence of arboviruses and other viral diseases (Nunes et al. 2009).

Segment S of OROV was also identified in pools of female Cx. quinquefasciatus captured in Cuiabá during the rainy season of 2013. Although low in frequency, infection in humans $(0.9 \%)$ and mosquitoes (MIR = 2.3 per 1,000 specimens) in the sampled populations 
indicates that OROV or other recombinant orthobunyavirus with the OROV segment $\mathrm{S}$ possibly circulate in the state. Consequently, outbreaks may take place under favourable conditions.

The different biotypes present in Cuiabá, are characterised by the existence of permanent preservation areas inside the urban perimeter, allowing the presence of host and vector species susceptible to arbovirus and, consequently, their occurrence in the human population. Lately, MT has undergone major environmental changes due to uncontrolled urban and agricultural expansion and the construction of new highways. Additionally, proximity to PA, RO and AM, where Oropouche fever cases are frequent, could have favoured the introduction OROV in MT. In this regard, IgM anti-OROV has been reported in residents of two cities from PA that border MT accessible via the Cuiabá-Santarém Highway (Nunes et al. 2009). This highway covers $1,780 \mathrm{~km}$ from Cuiabá to Santarém and is part of the BR-163 road, with 3,467 $\mathrm{km}$ of extension. This road crosses the country from the southern region through the coast of the Amazon River and the Trans-Amazonian Highway until Santarém. Anti-OROV serology in primates was also reported recently in MS (Batista et al. 2012, 2013).

Some authors have described a higher incidence of OROV infection in women (Dixon et al. 1981, Mourão et al. 2009). In this study, four of the five patients positive for segment $\mathrm{S}$ of OROV were women. Among the positive patients, only one reported a recent visit to rural areas. The other patients were urban residents without a history of travel or access to sylvatic or rural areas and were aged 14-62 years with different occupations, indicating the transmission may have occurred within the urban perimeter.

The positive patients were symptomatic for 48-72 h. Individuals with more than three days of symptoms probably were not detected due to low viraemic levels observed after the third day. For OROV, the reduction in viral titre is estimated at $72 \%$ on the third day and $44 \%$ and $23 \%$ on the fourth and fifth days, respectively, after the beginning of clinical signs, probably resulting in viraemic levels lower than the limit of detection by conventional diagnostic techniques (Pinheiro et al. 1981a).

The OROV nucleotide sequences of the $\mathrm{S}$ segment obtained from patients in MT present high identity with the S segment sequences of OROV strain AMLq16 obtained from the cerebrospinal fluid of one patient with aseptic meningitis in 2007 in Manaus (Bastos et al. 2012).

$C x$. quinquefasciatus has been considered a secondary vector for OROV. Natural infection of $C x$. quinquefasciatus by OROV captured in PA was demonstrated in 1968 (Pinheiro et al. 1976). In fact, OROV is the only Orthobunyavirus that has currently been described in this mosquito species. Successful experimental transmission between infected and susceptible hamsters was achieved only in the presence of high viraemic levels in the vertebrate model (Hoch et al. 1987). However, this experiment was not conducted with natural host species of the virus, such as primates, sloths and birds and experimental reproduction of a viral disease in animal models frequently requires higher titres of the virus in the inoculum than those observed during natural infection (Pinheiro et al. 1981b).

Vector competence can vary according to the population of the mosquito present in different geographical regions. This behavioural change has already been shown for other arboviruses such as SLEV and West Nile virus, which are transmitted by $C x$. quinquefasciatus (Reisen et al. 2005). Therefore, environmental factors can influence and change the competence of mosquitoes.

Despite of the maintenance of the specimens for more than $12 \mathrm{~h}$ on artificial feeding, the detection of segment $\mathrm{S}$ of OROV in Cx. quinquefasciatus captured in Cuiabá should be considered to result either from natural infection, especially in pools with nonengorged specimens or from blood meals in viraemic hosts in those pools with engorged specimens. Therefore, isolation of these viruses from nonengorged pools indicates that $C x$. quinquefasciatus is a potential vector for OROV or other viruses from the Simbu serogroup in MT. Nevertheless, the importance of $C x$. quinquefasciatus in the urban cycle of OROV is not completely understood or described in the literature. The involvement of $C x$. quinquefasciatus with factors such as low viraemic titres in humans may explain the low number of cases identified in this study. Additional studies are necessary to elucidate the vector competence of $C x$. quinquefasciatus for OROV or other orthobunyaviruses belonging to the Simbu serogroup in MT.

Specimens of C. paraensis or other Ceratopogonidae were not identified in this study. This result may be a result of either the absence of this species in the urban area of Cuiabá or the methodology used in this study. The chosen traps and period of capture might not be the most suitable for capturing biting midges (Santarém et al. 2010). Moreover, during epidemics, the isolation ratio of OROV in $C$. paraensis is considered extremely low (1:12.500). These data suggest that $C$. paraensis may be a low-efficiency vector and that other Culicidae may participate in the epidemiological cycle of OROV (LeDuc \& Pinheiro 1986).

In the sampled sectors, $C x$. quinquefasciatus presented a high potential for dispersion in different habitats. A study performed in Manaus demonstrated the temporal distribution of $C x$. quinquefasciatus throughout the year, with peaks in January and April, during the rainy season (Barbosa et al. 2008).

The characterisation of new species within the OROV complex requires at least $14.1 \%$ and $20.9 \%$ aa divergence of the S and L segments, respectively (Ladner et al. 2014). Phylogenetic analysis indicates that the segment $S$ OROV sequences obtained from humans and female $C x$. quinquefasciatus pools in this study belong to the subgenotype Ia, the most frequently reported subgenotype in humans in Brazil and shows close proximity to sequences of OROV obtained from the cerebrospinal fluid of humans in Manaus (Bastos et al. 2012), from human blood in AC (Terzian et al. 2009), from humans, sloths (B. tridactylus), Cx. quinquefasciatus and Ae. (Oc.) serratus in PA, beyond the prototype OROV TRVL-9760 (Fig. 3) (Saeed et al. 2000, Vasconcelos et al. 2009).

The Orthobunyavirus sequences identified in humans in this study presented a high similarity with those 
identified in mosquitoes, indicating the same virus is circulating in both populations. This virus may have dispersed from the Amazon Region to neighbouring states and $C x$. quinquefasciatus might be involved in the transmission cycle because the virus was identified in nonengorged pools and this species is considered a competent vector for OROV.

The segment $\mathrm{S}$ sequence obtained from sample CbaAR632 is very similar to and formed a cluster with the segment $\mathrm{S}$ sequence of OROV obtained from sloths (B. tridactylus) in PA in 1971 (Pinheiro et al. 1976) (Fig. 3). This pool, which contained two nonengorged $C x$. quinquefasciatus females, presented the most divergent sequences. The aa substitution found in this sample was also observed in OROV sequences from subgenotype Ia obtained from sloths (B. trydactilus) in PA (Nunes et al. 2005). Moreover, primates and birds that are known to participate in the transmission cycle of OROV are commonly found in the preservation areas and parks of Cuiabá. Another aa substitution was found in this pool at position 339 , which was reported previously only in human isolates of OROV from subgenotype IIa obtained in AP in 2009. A substitution at position 240 was observed previously in isolates from subgenotype IIIb obtained from Callithrix sp. in MG and from humans in MA, RO and $\mathrm{AC}$ and in Panamá (Vasconcelos et al. 2011). Although genotype I is considered the most stable, the mechanism of "boom and boost" evolution has also been reported for this genotype, resulting in emergence and posterior lineage replacement in the population (Zanotto et al. 1996).

A recent study suggests that nucleotide variations result from the selective pressure caused by the host in orthobunyaviruses. Therefore, sequences of the virus obtained from animals may have a different profile from those found in human and vector specimens. This characteristic is frequently observed within the $\mathrm{M}$ segment and is an important antigenic target that, due to the selective pressures and different geographical settings, can present high levels of nucleotide variation. Often, such variation can lead to a false interpretation of a reassortment (Tilston-Lunel et al. 2015). Because of its wide geographical distribution, viruses belonging to the Simbu serogroup present high levels of genetic diversity.

A phylogenetic study with species of the Simbu serogroup demonstrated that the three segments were consistent with their respective species with the exception of OROV, which presented various potential reassortment events (Ladner et al. 2014, Tilston-Lunel et al. 2015). In this study, it was not possible to obtain the sequences of the three segments due to the absence of viable biological samples from humans and the RNA extraction and sequencing methods selected for mosquito samples. However, there are limitations to the generation of new orthobunyaviruses by reassortment, such as the incompatibility of certain combinations, especially between distinct serogroups (Elliott 2014). Therefore, the detection of segment $\mathrm{S}$ of OROV suggests the possible circulation of this virus or a recombinant derivative of this virus in the state because, among orthobunyaviruses of the Simbu serogroup, OROV is the only species with recognised circulation in humans in Brazil.
Among the viruses belonging to the Simbu serogroup, Iquitos, Jatobal and Madre de Dios viruses are derived from OROV reassortment, belonging to the OROV serocomplex, and have been described in South America (Saeed et al. 2001, Aguilar et al. 2011, Ladner et al. 2014). OROV, Iquitos virus and Madre de Dios have been associated with human disease (Ladner et al. 2014). The only report of Jatobal virus, a reassortant with segment S from Peruvian strains of OROV, dates from 1984 in Brazil, when it was isolated from the blood of the South American coon (Nasua nasua) in PA (Saeed et al. 2001). The Iquitos and Madre de Dios viruses present segments $\mathrm{S}$ and $\mathrm{L}$ of OROV and $\mathrm{M}$ of another virus within the Simbu serogroup. The Iquitos virus was isolated from an outbreak that occurred only in Iquitos, Peru, in 1999 (Aguilar et al. 2011) and has never been described in Brazil. Likewise, Madre de Dios is a reassortant identified in humans only in Madre de Dios, Peru (Ladner et al. 2014). The Utinga virus, obtained from sloths (B. tridactylus), consists of a distinct species within the Simbu serogroup previously reported in Brazil, but never associated with human disease (Ladner et al. 2014).

Therefore, this is believed to be the first report of the circulation of an Orthobunyavirus with segment $\mathrm{S}$ of OROV in MT. Human cases may occur sporadically in the state, especially during dengue outbreaks. The similarity between the isolates identified in humans and $C x$. quinquefasciatus in this study suggests the same virus is circulating in both vertebrate and invertebrate hosts. Increased deforestation, urbanisation and human and animal circulation among different Amazonian subregions may contribute to the dissemination of arboviruses in Brazil.

\section{ACKNOWLEDGEMENTS}

To the professionals of LACEN-MT, for providing the human samples, to UFMT Veterinary Virology lab, for providing the structure to perform virus isolation, to Ricardo Heinen, for his assistance with ArcMap, and to Fiocruz Amazônia, for performing the nucleotide sequencing.

\section{REFERENCES}

Acrani GO, Gomes R, Proença-Módena JL, da Silva AF, Carminati PO, Silva ML, Santos RIM, Arruda E 2010. Apoptosis induced by Oropouche virus infection in HeLa cells is dependent on virus protein expression. Virus Res 149: 56-63.

Aguilar PV, Barret AD, Saeed MF, Watts DM, Russel K, Guevara C, Ampuero JS, Suárez L, Cespedes M, Montgomery JM, Halsey ES, Kochel TJ 2011. Iquitos virus: a novel reassortant Orthobunyavirus associated with human illness in Peru. PLoS Negl Trop Dis 5: e1315.

Anderson CR, Spence L, Downs WG, Aitken TG 1961. Oropouche virus: a new human disease agent from Trinidad, West Indies. $\mathrm{Am}$ J Trop Med Hyg 10: 574-578.

Barbosa MD, Fé NF, Marcião AH, Silva AP, Monteiro WM, Guerra MV, Guerra JA 2008. Record of epidemiologically important Culicidae in the rural area of Manaus, Amazonas. Rev Soc Bras Med Trop 41: 658-663.

Bastos MS, Figueiredo LTM, Naveca FG, Monte RL, Lessa N, Figueiredo RMP, Gimaque JBL, João GP, Ramasawmy R, Mourão MPG 2012. Identification of Oropouche Orthobunyavirus in the cerebrospinal fluid of three patients in the Amazonas, Brazil. Am J Trop Med Hyg 86: 732-735. 
Batista PM, Andreotti R, Almeida PS, Marques AC, Rodrigues SG, Chiang JO, Vasconcelos PF 2013. Detection of arboviruses of public health interest in free-living New World primates (Sapajus spp; Alouatta caraya) captured in Mato Grosso do Sul, Brazil. Rev Soc Bras Med Trop 46: 684-690.

Batista PM, Andreotti R, Chiang JO, Ferreira MS, Vasconcelos PF 2012. Seroepidemiological monitoring in sentinel animals and vectors as part of arbovirus surveillance in the state of Mato Grosso do Sul, Brazil. Rev Soc Bras Med Trop 45: 168-173.

Becker BK 2001. Revisão das políticas de ocupação da Amazônia: é possível identificar modelos para projetar cenários? Parcerias Estratégicas 12: 135-159.

Borborema CAT, Pinheiro FP, Albuquerque BC, Rosa PA, Rosa JF, Dourado HV 1982. Primeiro registro de epidemias causadas pelo vírus Oropouche no estado do Amazonas. Rev Inst Med Trop Sao Paulo 24: 132-139.

Chowdhary R, Street C, Travassos da Rosa A, Nunes MRT, Tee KK, Hutchison SK, Vasconcelos PFC, Tesh RB, Lipkin WI, Briese T 2012. Genetic characterization of the Wyeomyia group of orthobunyaviruses and their phylogenetic relationships. J Gen Virol 93: 1023-1034.

Dixon KE, Travassos da Rosa AP, Travassos da Rosa JF, Llewellyn CH 1981. Oropouche virus. II. Epidemiological observations during an epidemic in Santarém, Pará, Brazil in 1975. Am J Trop Med Hyg 30: 161-164.

Elliott RM 2014. Orthobunyaviruses: recent genetic and structural insights. Nat Rev Microbiol 12: 673-685.

Figueiredo LTM 1999. Brazilian viruses in the family Bunyaviridae. Rev Medicina-Ribeirão Preto 32: 154-158.

Figueiredo LTM, Travassos da Rosa APA, Fiorillo AM 1986. Níveis de anticorpos para arbovírus em indivíduos da região de Ribeirão Preto, SP (Brasil). Rev Saude Publica 20: 204-211.

Forattini OP 2002. Culicidologia médica. Culicidae, vol. II, EDUSP, São Paulo, 548 pp.

Gauci PJ, McAllister J, Mitchell IR, Boyle DB, Bulach DM, Weir RP, Melville LF, Gubala AJ 2015. Genomic characterisation of three Mapputta group viruses, a serogroup of Australian and Papua New Guinean Bunyaviruses associated with human disease. PLoS ONE 3: 1-18.

Hang J, Forshey BM, Yang Y, Solórzano VF, Kuschner RA, Halsey ES, Jarman RG, Kochel TJ 2014. Genomic characterization of group C Orthobunyavirus reference strains and recent South American clinical isolates. PLoS ONE 9: e92114.

Heinen LBS, Zuchi N, Cardoso BF, Santos FAL, Santos MAM, Nogueira ML, Dezengrini-Slhessarenko R 2015. Dengue outbreak in Mato Grosso, West-Central Brazil. Rev Inst Med Trop 57: $215-220$

Hoch AL, Pinheiro FP, Roberts DR, Gomes MLC 1987. Laboratory transmission of Oropouche virus by Culex quinquefasciatus Say. PAHO Bulletin 21: 51-61.

Ladner JT, Savji N, Lofts L, Travassos da Rosa A, Wiley MR, Gestole MC, Rosen GE, Guzman H, Vasconcelos PF, Nunes MR, Kochel TJ, Lipkin WI, Tesh RB, Palacios G 2014. Genomic and phylogenetic characterization of viruses included in the Manzanilla and Oropouche species complexes of the genus Orthobunyavirus, family Bunyaviridae. J Gen Virol 95: 1055-1066.

LeDuc JW, Pinheiro FP 1986. Oropouche fever. In TP Monath (ed.), The arboviruses: epidemiology and ecology, CRC Press, Boca Raton, p. 1-14.

Lins TC, Vieira RG, Abreu BS, Grattapaglia D, Pereira RW 2010. Genetic composition of Brazilian population samples based on a set of twenty eight ancestry informative SNPs. Am J Hum Biol 22: $187-192$
Moreli ML, Aquino VH, Cruz AC, Figueiredo LT 2002. Diagnosis of Oropouche virus infection by RT-nested-PCR. J Med Virol 66: 139-142.

Moreli ML, Costa VG 2013. A systematic review of molecular diagnostic methods for the detection of arboviruses in clinical specimens in Brazil and the importance of a differential diagnosis. Virology Discovery 1: 1-7.

Mourão MP, Bastos MS, Gimaqu JB, Mota BR, Souza GS, Grimmer GH, Galusso ES, Arruda E, Figueiredo LT 2009. Oropouche fever outbreak, Manaus, Brazil, 2007-2008. Emerg Infect Dis 15: 2063-2064.

Murphy FA 1998. Emerging zoonosis. Emerg Infect Dis 4: 429-435.

Nunes MR, Barbosa TF, Casseb LM, Nunes Neto JP, Segura NO, Monteiro HA, Pinto EV, Casseb SM, Chiang JO, Martins LC, Medeiros DB, Vasconcelos PF 2009. Eco-epidemiologia dos arbovírus na área de influência da Rodovia Cuiabá-Santarém (BR 163), estado do Pará, Brasil. Cad Saude Publica 25: 2583-2602.

Nunes MR, Martins LC, Rodrigues SG, Chiang JO, Azevedo RS, Rosa AP, Vasconcelos PF 2005. Oropouche virus isolation, Southeast Brazil. Emerg Infect Dis 11: 1610-1613.

Pinheiro FP 1983. Febre do Oropouche. J Bras Med 44: 46-62.

Pinheiro FP, Hoch AL, Gomes MLC, Roberts DR 1981a. Oropouche virus. IV. Laboratory transmission by Culicoides paraensis. Am J Trop Med Hyg 30: 172-176.

Pinheiro FP, Pinheiro M, Bensabath G, Causey OR, Shope RE 1962. Epidemia de vírus Oropouche em Belém. Rev Serv Saude Publica 12: $15-23$.

Pinheiro FP, Travassos da Rosa AP, Travassos da Rosa JF, Bensabath G 1976. An outbreak of Oropouche disease in the vicinity of Santarém, Pará, Brazil. Tropenmed Parasitol 27: 213-223.

Pinheiro FP, Travassos da Rosa AP, Travassos da Rosa JF, Ishak R, Freitas RB, Gomes ML, LeDuc JW, Oliva OF 1981b. Oropouche virus. I. A review of clinical, epidemiological and ecological findings. Am J Trop Med Hyg 30: 149-160.

Pinheiro FP, Travassos da Rosa APA, Freitas RB 1986. Virologia: aspectos clínico-epidemiológicos. In FP Pinheiro, APA Travassos da Rosa, RB Freitas (eds.), 50 anos de contribuição às ciências biológicas e à medicina tropical, Instituto Evandro Chagas, Belém, p. 375-408.

Pinheiro FP, Travassos da Rosa APA, Vasconcelos PFC 1997. Febre por Oropouche. In NQ Leão (ed.), Doenças infecciosas e parasitárias: enfoque amazônico, CEJUP, Belém, p. 285-298.

Pinheiro FP, Travassos da Rosa APA, Vasconcelos PFC 1998. An overview of Oropouche fever epidemics in Brazil and neighboring countries. In APA Travassos da Rosa, PFC Vasconcelos, JFS Travassos da Rosa (eds.), An overview of arbovirology in Brazil and neighboring countries, Instituto Evandro Chagas, Belém, p. 186-192.

Reisen WK, Fang Y, Martinez VM 2005. Avian host and mosquito (Diptera: Culicidae) vector competence determine the efficiency of West Nile and St. Louis encephalitis virus transmission. J Med Entomol 42: 367-375.

Saeed MF, Wang H, Nunes M, Vasconcelos PF, Weaver SC, Shope RE, Watts DM, Tesh RB, Barrett AD 2000. Nucleotide sequences and phylogeny of the nucleocapsid gene of Oropouche virus. $J$ Gen Virol 81: 743-748.

Saeed MF, Wang H, Suderman M, Beasley DWC, Travassos da Rosa A, Li L, Shope RE, Tesh RB, Barrett ADT 2001. Jatobal virus is a reassortant containing the small RNA of Oropouche virus. Virus Res 77: 25-30.

Santarém MCA, Confalonieri UEC, Felippe-Bauer ML 2010. Diversidade de Culicoides (Diptera: Ceratopogonidae) na Floresta Nacional de Caxiuanã, Melgaço, estado do Pará, Brasil. Rev PanAmaz Saude 1: 29-33. 
Smith JL, Fonseca DM 2004. Rapid assays for identification of members of the Culex (Culex) pipiens complex, their hybrids and other sibling species (Diptera: Culicidae). Am J Trop Med Hyg 70: 339-345.

Terzian ACB, Bronzoni RVM, Drumond BP, Nunes MS, Silva NS, Ferreira MU, Sperança MA, Nogueira ML 2009. Sporadic Oropouche virus infection, Acre, Brazil. Emerg Infect Dis 15: 348-350.

Tilston-Lunel NL, Hughes J, Acrani GO, da Silva DE, Azevedo RS, Rodrigues SG, Vasconcelos PF, Nunes MR, Elliott RM 2015. A genetic analysis of the Oropouche virus species and identification of a novel M segment sequence. J Gen Virol: doi: 10.1099/ vir.0.000108

Vasconcelos HB, Azevedo RS, Casseb SM, Nunes-Neto JP, Chiang JO, Cantuária PC, Segura MN, Martins LC, Monteiro HA, Rodrigues SG, Nunes MR, Vasconcelos PF 2009. Oropouche fever epidemic in northern Brazil: epidemiology and molecular characterization of isolates. J Clin Virol 44: 129-133.

Vasconcelos HB, Nunes MR, Casseb LM, Carvalho VL, da Silva EVP,
Silva M, Casseb SM, Vasconcelos PF 2011. Molecular epidemiology of Oropouche virus, Brazil. Emerg Infect Dis 17: 800-806.

Vasconcelos PFC, Travassos da Rosa GFS, Guerreiro SC, Dégallier N, Travassos da Rosa ES, Travassos da Rosa APA 1989. Primeiro registro de epidemias causadas pelo vírus Oropouche nos estados do Maranhão e Goiás, Brasil. Rev Soc Bras Med Trop 31: 271-278.

Yanase T, Kato T, Aizawa M, Shuto Y, Shirafuji H, Yamakawa M, Tsuda T 2012. Genetic reassortment between Sathuperi and Shamonda viruses of the genus Orthobunyavirus in nature: implications for their genetic relationship to Schmallenberg virus. Arch Virol 157: 1611-1616.

Zanotto PMA, Gibbs MJ, Gould EA, Holmes ECA 1996. Reevaluation of the higher taxonomy of viruses based on RNA polymerases. J Virol 70: 6083-6096.

Zuchi N, Heinen LBS, dos Santos MAM, Pereira FC, Slhessarenko RD 2014. Molecular detection of Mayaro virus during a dengue outbreak in the state of Mato Grosso, Central-West Brazil. Mem Inst Oswaldo Cruz 109: 820-823. 